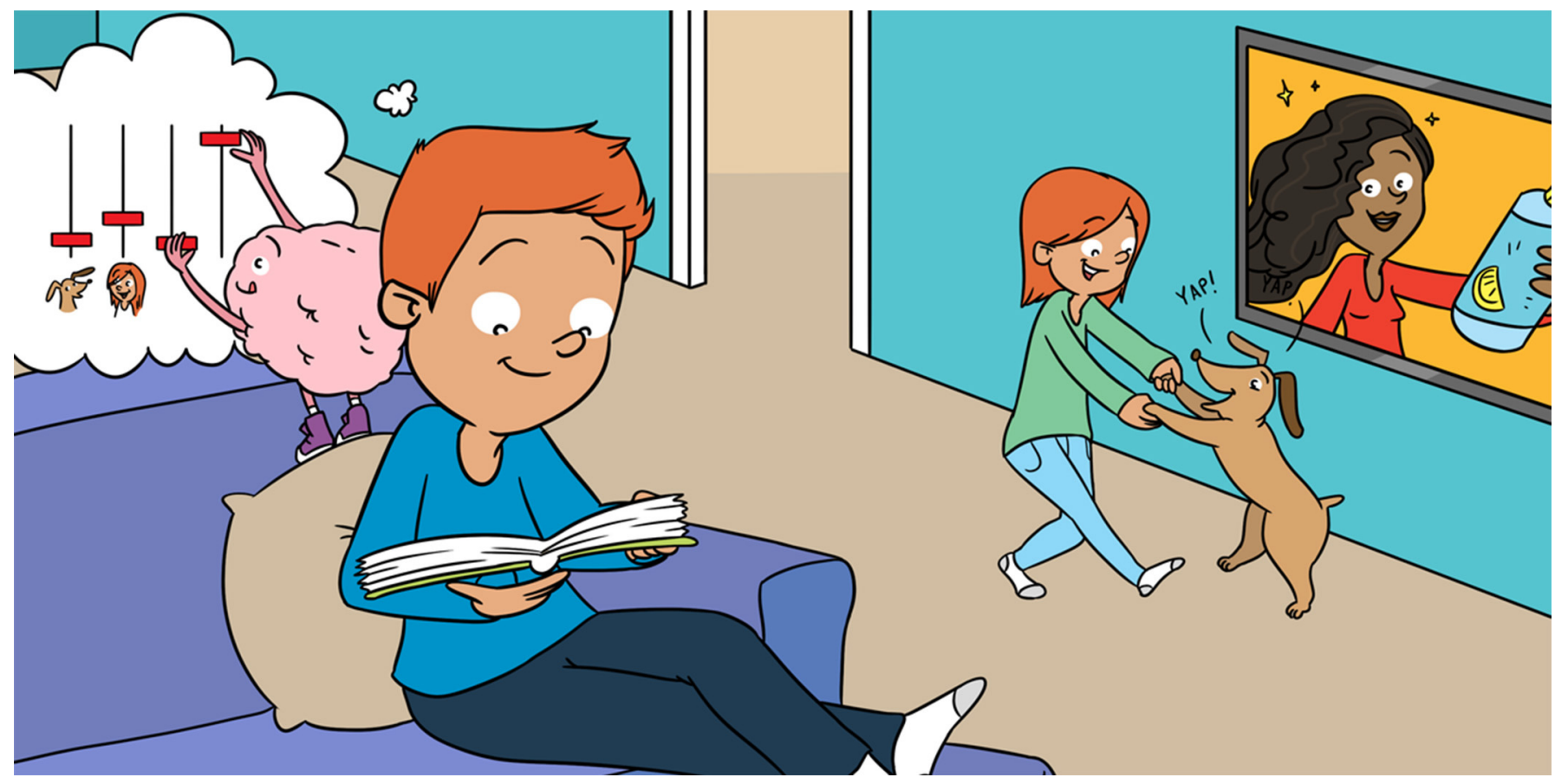

\title{
HOW WE PAY ATTENTION
}

\section{George R. Mangun *}

Center for Mind and Brain, University of California, Davis, Davis, CA, United States

YOUNG REVIEWERS:

DUKE

UNIVERSITY

NEUROSCIENCES

CAMP

AGES: $15-17$
How are you able to focus on your homework when your sister is running around the room chasing the dog? Your brain helps you do that, by changing the intensity of the sights and sounds coming from the distracting play of your sister. Sensory signals entering your brain through your eyes and ears have to be processed in sensory brain areas, and the brain's attention system helps you to manage sensory information so that the most important information is processed with high priority. Scientists can record the electrical signals in the brain to show that paying attention changes the strength of the signals. The remarkable thing about your ability to filter sensory information is that what you want or need to see or hear is mostly what you do see and hear. Thus, your brain does not simply record everything that happens around you like a video camera-instead, it helps you limit your perceptions to the most important things.

\section{NOW YOU SEE IT, NOW YOU DO NOT}

When I was a kid, my father liked to lay on the floor to watch TV. Sometimes my siblings or I would ask him a question about something 


\section{SELECTIVE}

\section{ATTENTION}

The ability of organisms to pay attention to the most important sensory events, thoughts, or actions, while ignoring less important or distracting ones.

\section{REACTION TIME}

How long it takes a person to press a button after something happens. Reaction time is often measured in milliseconds, or thousandths of a second. on the show, but he would not answer us. We would say, "Dad...", "Dad...!", "DAD!", but he seemed not to hear. We would then run over and start waving at him, and he would still not respond until we got between him and the TV, at which point he would laugh and ask us what we wanted.

One day (when he was not watching TV) I asked my dad why he did not hear or see us until we were right in front of him, and his answer was clear-he said he was simply paying attention to the interesting TV show. At the time, I did not understand how our loud voices could not attract his attention, but now, some decades later, I am beginning to understand. The brain has powerful mechanisms that permit us to focus our attention on some things (like a TV show) and avoid other distracting sounds or sights (like kids yelling and waving). We call this ability of organisms to pay attention to relevant information selective attention [1], and we now know a lot about how the brain does this.

\section{MEASURING ATTENTION IN THE LABORATORY}

How can we measure something that is going on inside our brains, like our ability to pay attention? Scientist Michael Posner developed a powerful tool to measure visual attention, which is the attention we pay to things we see [2]. He had college students do a simple test, in which they watched a computer screen, keeping their eyes focused on a plus sign in the middle of the screen. Pictures briefly flashed on the screen (simple figures, like circles or squares), and the students had to press a button as fast as they could, as soon as they saw the pictures. This way, Posner could measure their reaction times (time between the appearance of the picture and when they pressed the button). But he did something else in addition-prior to flashing each picture, he gave the students important information about where on the screen the picture was most likely to appear. He used a simple arrow to indicate whether the picture would be on the right side or the left side of the screen (Figure 1). But, about 10\% of the time, the arrow was wrong. How did this affect reaction time?

Posner found that, when the arrow correctly predicted the location of the picture, the students had faster reaction times than they did when the arrow and the location of the picture did not match. The difference in reaction time when the picture appeared where it was expected compared with the unexpected location is the reaction time measure of visual attention. In the task described here, the students paid attention to the picture at one spatial location (expected location) while ignoring the other location (unexpected location), and so we call this "spatial attention" to distinguish it from situations where the color or form of an object defines its importance, instead of its location. 
Figure 1

How does attention influence reaction time? The four gray boxes represent computer monitors. In the top row, as the participant stares at the plus sign in the middle of the screen, an arrow cue appears that points to the left. After a delay of about $1 \mathrm{~s}$, the target picture (white rectangle) appears at the expected location (left side of the monitor). Without looking away from the plus sign, the participant must push a button as fast as they can, but not before, the target picture appears. When the arrow predicts the target location, the reaction time to push the button is relatively fast (green bar in upper right graph). When the arrow incorrectly predicts the location of the target, as seen in the bottom row, the reaction time is slower (green bar in the bottom right graph).

\section{ELECTROENCE-} PHALOGRAM (EEG)

A recording of the brain's electrical signals, made using electrodes placed on the human scalp.

EVENT-RELATED POTENTIAL (ERP)

An event-related potential is the scalp-recorded electrical signal from the brain that is determined from the EEG using signal averaging methods. As the name implies, and

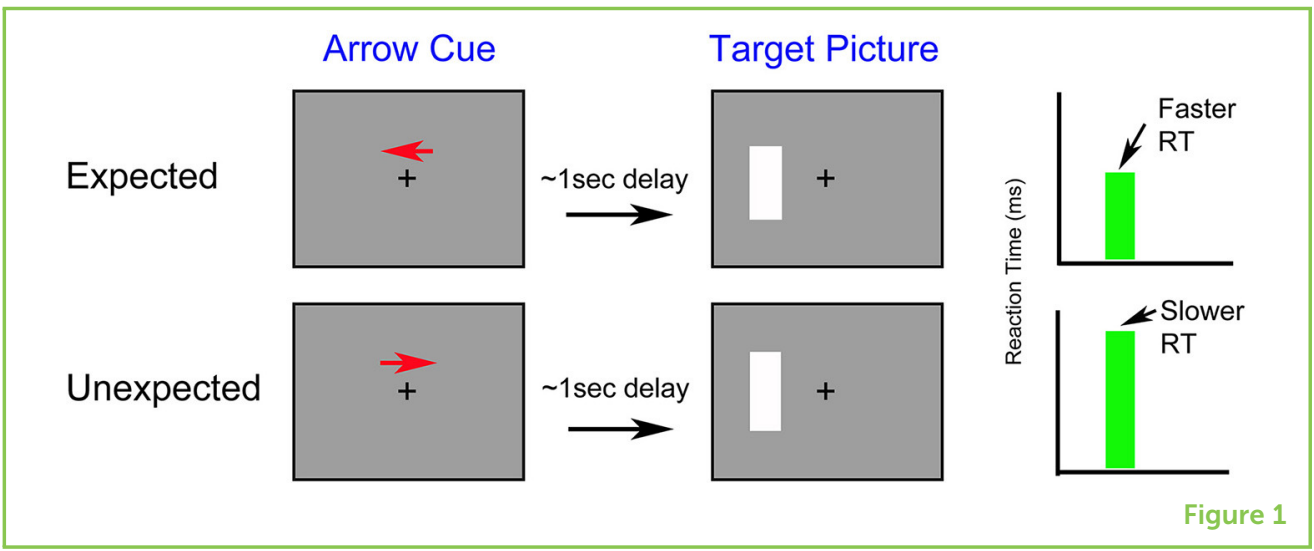

\section{BRAIN ACTIVITY WHILE PAYING ATTENTION}

So, what exactly happens in the brain that causes faster reaction times for the expected (attended) pictures in the activity we described above? In humans, one powerful method used to examine what is going on inside the brain is to record the electrical activity produced by the brain when it is active. Brain cells (neurons) send information to one another using small electrical signals. These tiny electrical signals can flow up through the tissues and across the skull and scalp, where they can be recorded using electrodes (small metal disks) attached to the scalp. Electrical devices called amplifiers boost the tiny signals so we can observe them more easily. This method is called electroencephalography (EEG) and the recorded signals are called electroencephalograms (EEGs or EEG signals).

The EEG signal is produced by the activity of thousands or millions of neurons in the brain, and contains lots of different electrical signals coming from multiple different brain regions at any particular moment. For example, an EEG signals will contain electrical activity related to seeing the white rectangle shown in Figure 1, but will also contain other electrical signals, like those representing the brain's response to any sounds the person hears while performing the task (e.g., music or conversation in the background). So, scientists have to use a clever method, called signal averaging, to figure out which electrical signals actually come from seeing the rectangle. This is done separately for the rectangles flashed at the expected and the unexpected locations. The electrical signal that is specific for the activity being studied is called the event-related potential (ERP). Let us break this term down: From the EEG, we are looking at the electrical potentials that are related to a particular event being studied-the appearance of the white rectangle [3]. For simplicity, we can just refer to these ERPs as brain waves.

It has been known since the work of scientists like Robert Eason and Steven Hillyard in the 1970's [4, 5] that the brain waves that occur in response to both visual and auditory events change depending on whether the person is paying attention to the sight or sound or 
ERP reflects the potential (the electrical signal) that is related to an event, like the appearance of a target picture. ignoring it. In the experiment we described, we saw that the brain waves were larger for the target picture when it appeared in the expected location than if it appeared in the unexpected location (Figure 2). This means that the visual neurons in the brain had a bigger electrical response when the study participants were paying attention to the expected location when the target appeared. So, the sensory signals that we pay attention to are boosted in the brain and the ones we do not pay attention to are reduced, like turning the volume on the radio up or down [6]. As you might have guessed, the target picture that produces a larger brain response also leads to a faster reaction time. You might also have guessed that the brain waves that happen when paying attention are quicker, leading to the faster motor reaction times, but that is not the finding. Instead, larger, stronger brain signals, not quicker ones, lead to faster reaction times. Why? Well, we believe the larger electrical signals mean that the brain's processing of the pictures is enhanced, and this larger signal produces a strong brain response that can then result in faster processing in the brain, and also faster movements, resulting in quicker reaction times.

\section{WHAT DOES THIS MEAN ABOUT HOW WE ARE ABLE TO PAY ATTENTION?}

Let us consider the case of my father watching TV that I used to open this article. While he was focusing his attention on the pictures on the TV, his brain was increasing the visual (and auditory) responses to the TV show in his brain and suppressing other inputs that he was not interested in at that time. So, when my siblings and I asked him questions, the reason he did not seem to see or hear us is that the signals in his brain produced by our voices and faces were being suppressed, because his attention was focused on the TV. All these years later, we can be reassured that our father loved us and that he was not pretending to not hear or see us, because science has explained why he did not respond right away-his brain attention system was doing its job, helping him focus intensely on the interesting TV show. When you focus your attention, your brain is doing the same thing - it is changing the strength of the sights and sounds (and touches, and smells and tastes) in the world to help you do a good job, whatever that job might be.

\section{WHY IS THIS IMPORTANT?}

Think about it for a moment-do you really perceive everything that is in front of you? Try searching a drawer of junk to find something you need-is it easy? If you need to study for an exam, does it help or hurt to have loud music, the TV, or other distractions? Attention is a basic brain function that humans (and animals) need so they can perform tasks effectively, and so that they can learn and survive in a potentially dangerous world. Attention lets you focus on the most 
Figure 2

Measuring brain waves during an attention task. (Top) As in Figure 1 , an arrow signals the expected location of the white rectangle that will appear about $1 \mathrm{~s}$ later. In response to the arrow, the person shifts their attention to the expected location (dotted black lines), while keeping his eyes focused on the + sign (solid black lines). (Bottom) The brain waves in response to the task are determined by signal averaging the $E E G$, and are then plotted. The plot shows the strength of the brain's electrical signal (y-axis) over time ( $x$-axis). " $t=0$ " shows the time the rectangle appeared on the screen. The fluctuating lines are the brain waves, and they show a larger electrical response (in microvolts) to the rectangle when the person is paying attention to the location where it appears (red line) compared with the situation in which the person's attention is directed to the right (dashed blue line) and they are therefore ignoring the left target picture.

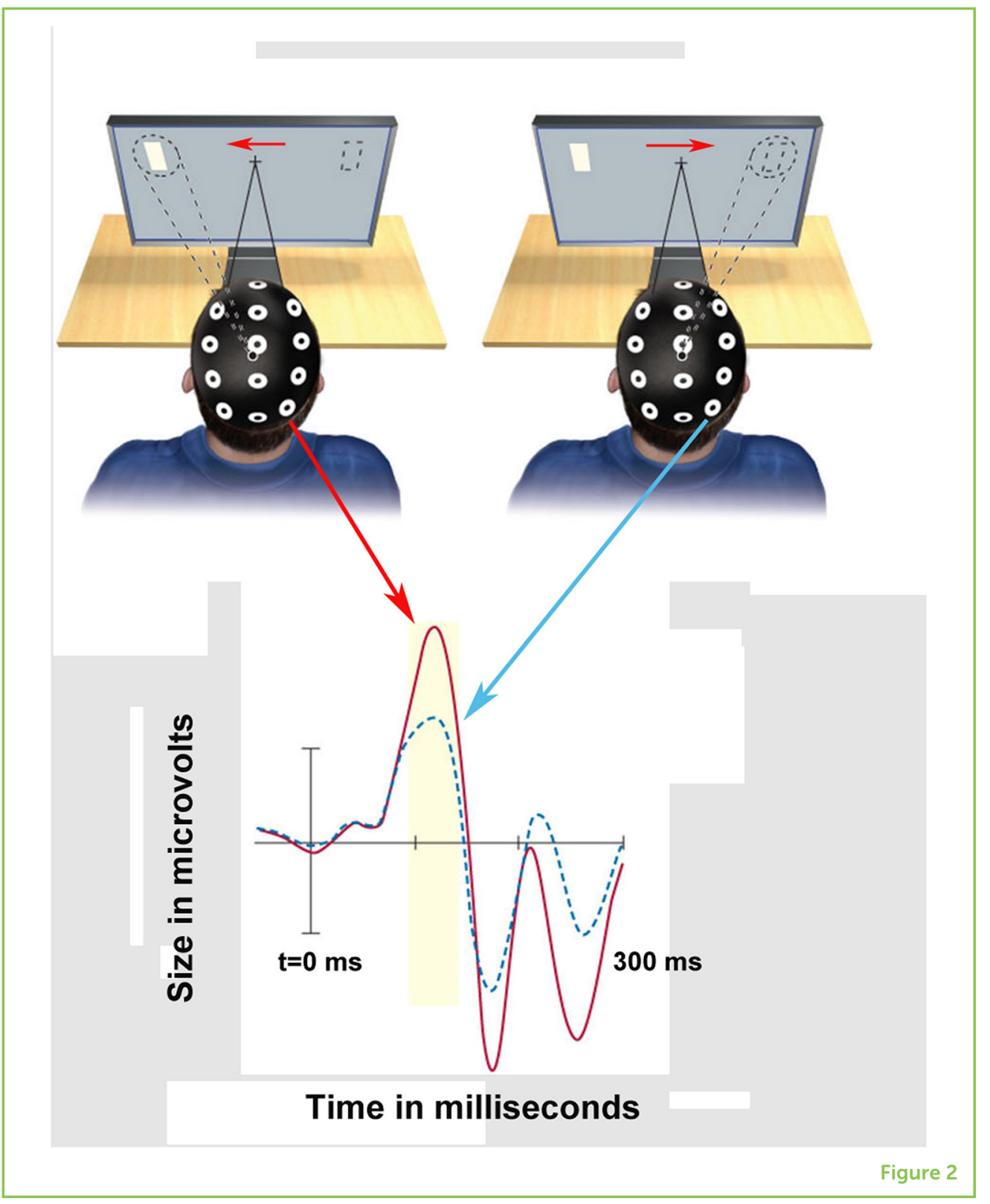

important things at the time to prevent distraction from leading to disaster, and the brain has evolved powerful methods to do just that. These mechanisms arose early in evolution, not just in mammals or humans, but in simple organisms, too. Over the course of evolution, these mechanisms have become increasingly refined and powerful, and help humans to focus on what is most important at the moment. Whether stalking a prey animal by following its tracks, or focusing on a challenging exam question, attention is there to help us succeed.

Understanding how the brain enables selective attention is also important for the treatment of certain disabilities, like attention deficit disorder, which affects a significant portion of the population and results in diminished ability to focus attention and prevent distraction. Many other disorders also involve problems with attention, so 
scientists and doctors need to understand the details of how the brain's attention system works, in order to develop treatments to correct the many forms of attention problems that people can experience.

\section{REFERENCES}

1. Posner, M. I. 2008. Measuring alertness. Ann. N. Y. Acad. Sci. 1129:193-9. doi: 10.1196/annals.1417.011

2. Posner, M. I., Snyder, C. R., and Davidson, B. J. 1980. Attention and the detection of signals. J. Exp. Psychol. 109:160-74.

3. Luck, S. J., Woodman, G. F., and Vogel, E. K. 2000. Event-related potential studies of attention. Trends Cogn. Sci. 4:432-40. doi: 10.1016/s1364-6613(00)01545-x

4. Van Voorhis, S., and Hillyard, S. A. 1977. Visual evoked potentials and selective attention to points in space. Percept. Psychophys. 22:54-62

5. Eason, R., Harter, M., and White, C. 1969. Effects of attention and arousal on visually evoked cortical potentials and reaction time in man. Physiol.

Behav. 4:283-9.

6. Mangun, G. R., and Hillyard, S. A. 1991. Modulations of sensory-evoked brain potentials indicate changes in perceptual processing during visual-spatial priming. J. Exp. Psychol. Hum. Percept. Perform. 17:1057-74

SUBMITTED: 22 May 2019; ACCEPTED: 27 February 2020;

PUBLISHED ONLINE: 23 March 2020.

EDITED BY: Gideon Paul Caplovitz, University of Nevada, Reno, United States

CITATION: Mangun GR (2020) How We Pay Attention. Front. Young Minds 8:29. doi: 10.3389/frym.2020.00029

CONFLICT OF INTEREST: The author declares that the research was conducted in the absence of any commercial or financial relationships that could be construed as a potential conflict of interest.

COPYRIGHT (c) 2020 Mangun. This is an open-access article distributed under the terms of the Creative Commons Attribution License (CC BY). The use, distribution or reproduction in other forums is permitted, provided the original author(s) and the copyright owner(s) are credited and that the original publication in this journal is cited, in accordance with accepted academic practice. No use, distribution or reproduction is permitted which does not comply with these terms.

\section{YOUNG REVIEWERS}

\section{DUKE UNIVERSITY NEUROSCIENCES CAMP, AGES: 15-17}

Duke Neuroscience Camp is a part of Duke Youth Programs. We accept applications from high school students from all over the world. Anyone can join, and no prior experiences are required. The only thing needed is an interest in neuroscience! The group enjoyed learning about how science happens, from lab tours at Duke to a taste of the peer-review pipeline with Frontiers. 


\section{AUTHOR}

\section{GEORGE R. MANGUN}

George R. Mangun is a Distinguished Professor of Psychology and Neurology, and the Director of the Center for Mind and Brain, at the University of California, Davis. He received his doctoral degree in neuroscience from the University of California, San Diego, in 1987. His research investigates brain attention mechanisms using advanced brain recording and imaging tools. He served as Editor of Cognitive Brain Research, and Associate Editor for the Journal of Cognitive Neuroscience, and was a member of the founding committee of the Cognitive Neuroscience Society. His popular textbook, Cognitive Neuroscience: The Biology of the Mind (W.W. Norton, publishers), written together with Professors Richard Ivry and Michael Gazzaniga, is now in its fifth edition (2019) and has sold more than 100,000 copies worldwide. Professor Mangun is an elected fellow of the Association for Psychological Science, and the American Association for the Advancement of Science. *mangun@ucdavis.edu 